\title{
ATENDIMENTO PSICOLÓGICO A ESTUDANTES UNIVERSITÁRIOS: CONSIDERAÇÕES ACERCA DE UMA EXPERIÊNCIA EM CLÍNICA-ESCOLA*
}

\author{
PSYCHOLOGICAL SERVICE TO UNIVERSITY \\ STUDENTS: CONSIDERATIONS ABOUT AN \\ EXPERIENCE IN PSYCHOLOGICAL UNIVERSITY CLINIC
}

\author{
Rodrigo Sanches PERES ${ }^{1}$ \\ Manoel Antônio dos SANTOS ${ }^{2}$ \\ Heidi Miriam Bertolucci COELHO ${ }^{3}$
}

\begin{abstract}
RESUMO
O presente estudo tem como objetivo descrever o Programa de Pronto-Atendimento Psicológico ao Aluno (PPAPA). Trata-se de um serviço de atendimento psicológico oferecido gratuitamente junto à clínica-escola da Faculdade de Ciências e Letras de Assis (UNESP) e voltado exclusivamente à comunidade discente interna. Apresentaremos ao longo do artigo uma breve caracterização do serviço, algumas considerações acerca das modalidades de atendimento e estratégias de intervenção empregadas e uma sucinta problematização do manejo de questões técnicas e éticas. Por fim, alinhavaremos algumas propostas para a reestruturação do serviço.
\end{abstract}

Palavras-chave: clínica-escola de psicologia; serviço de triagem psicológica; pronto-atendimento psicológico; psicoterapia.

\footnotetext{
(*) Uma versão preliminar do presente estudo foi apresentada no XXVIII Simpósio Interamericano de Psicologia, Santiago (Chile).

(1) Universidade de São Paulo/Ribeirão Preto - Endereço para Correspondência: R: Jesuíno de Arruda, 2753 Centro - Cep: 13560-060 - São Carlos/SP - E-mail: rodrigo_sanches_peres@hotmail.com

(2) Universidade de São Paulo/Ribeirão Preto.

(3) Universidade Estadual Paulista/Assis.
} 


\section{SUMMARY}

The present study aims to describe a Student Psychological Emergency Service. This gratuitous service is offered at the university psychology clinic of Faculdade de Ciências e Letras de Assis (UNESP) and is exclusively available to the university students. A brief characterization of the service will be presented along the article, considering the modalities of the service, intervention strategies and a concise argumentation on the technical and ethical issues. Finally, it will be offered some suggestions for reorganization of the service.

Key words: psychological university clinic; psychological screening service; psychotherapy; psychoanalysis.

\section{INTRODUÇÃO}

As clínicas-escola de Psicologia têm como finalidade básica possibilitar o treinamento de alunos, mediante a aplicação prática dos conhecimentos teóricos adquiridos em sala de aula, o que pode contribuir para a formação de profissionais adequadamente habilitados e capazes de expandir os fazeres psicológicos em consonância com as novas realidades e demandas sociais, políticas e culturais da atualidade. Além disso, as clínicas-escola também exercem um papel social de extrema importância, uma vez que oferecem à população economicamente desfavorecida uma possibilidade de acesso a serviços psicológicos gratuitos ou de baixo custo financeiro (Herzberg, 1996).

Em virtude da relevância do tema, os diversos tipos de intervenções desenvolvidas junto às clínicas-escola têm sido objeto de vários estudos recentes, que focalizam, em linhas gerais, desde a caracterização da clientela (Santos et al., 1993; Enéas et al., 2000; Peres \& Coelho, 2002a e 2002b) e a descrição dos serviços oferecidos (Santos, 1987; Vaisberg \& Machado, 1999; Silvares, 2000; Mito, 2001) até a problematização das dificuldades inerentes ao trabalho clínico-institucional (Silvestre, 1987; Bezerra Jr., 1987; Tozoni-Reis, 1994; Silvares, 1996) e a elaboração de novas propostas de intervenção que diferem, em maior ou menor grau, das modalidades de atendimento tradicionalmente oferecidas (Calejón, 1996;
Yamamoto, 1997; Barros et al., 2001; Salinas \& Santos, 2002). Tais estudos têm se mostrado imprescindíveis tanto para o aprimoramento das práticas clínicas já existentes - a partir da avaliação da resolutividade das mesmas e da identificação das reais necessidades da população - quanto para a criação de novos serviços ou modalidades de atendimento.

A maior parte dos estudos que adota como temática serviços oferecidos em clínicas-escola refere-se a intervenções voltadas à comunidade externa, ou seja, à população da cidade e/ou região na qual a instituição mantenedora está inserida. Com exceção de alguns poucos trabalhos, tais como os de Simon (1971), Calejón (1996) e Yamamoto (1997), são incomuns na literatura científica especializada estudos nacionais que abordam serviços oferecidos em clínicas-escola e direcionados especificamente à comunidade discente interna. Dessa forma, pode-se supor que a maioria das clínicas-escola do país dedica pouca - ou nenhuma - atenção aos alunos da própria instituição, o que representa, a nosso ver, um contra-senso injustificável.

O presente estudo tem como objetivo descrever um serviço de atendimento psicológico oferecido junto à clínica-escola da Faculdade de Ciências e Letras de Assis da Universidade Estadual Paulista (UNESP), voltado exclusivamente à comunidade discente interna. Assim sendo, apresentaremos ao longo do texto basicamente: a) uma breve caracterização do 
serviço; b) considerações acerca das modalidades de atendimento e estratégias de intervenção empregadas; c) uma sucinta problematização do manejo de questões técnicas e éticas e d) algumas propostas para a reestruturação do serviço.

\section{CARACTERÍSTICAS GERAIS DO CONTEXTO NO QUAL O SERVIÇO SE ENCONTRA INSERIDO}

Antes de caracterizar o serviço em questão, as modalidades de atendimento praticadas e as estratégias de intervenção utilizadas, consideramos relevante delinear o contexto no qual o serviço se encontra inserido. Assis é um município de aproximadamente 90 mil habitantes situado no oeste do Estado e distante cerca de 450 quilômetros de São Paulo. Possui um perfil econômico diversificado, com base na agricultura e comércio, de modo que se tornou nos últimos anos o principal município do Médio Paranapanema. A Faculdade de Ciências e Letras de Assis foi criada em 1958 e conta, nos dias de hoje, com quatro cursos de graduação - Psicologia, Letras, História e Biologia - distribuídos em uma área de $125.000 \mathrm{~m}^{2}$. No ano de 2001 encontravam-se regularmente matriculados em tais cursos 1439 alunos, sendo em sua maior parte provenientes de outras cidades do Estado de São Paulo e até mesmo de outras regiões do país.

\section{CARACTERÍSTICAS GERAIS DO SERVIÇO}

Criado em 1998, o Programa de Pronto-Atendimento Psicológico ao Aluno (PPAPA) tem como intuito básico oferecer atendimento psicológico aos alunos dos cursos de graduação da unidade. O referido serviço foi implementado em virtude da necessidade de, em um primeiro momento, organizar e otimizar os recursos da instituição para que fosse possível, em um segundo momento, prestar assistência aos alunos que, em número cada vez maior, solicitavam atendimento psicológico junto à clínica-escola da unidade (Centro de Pesquisas e Psicologia Aplicada - CPPA).

Os atendimentos oferecidos pelo serviço são gratuitos, conduzidos por estagiários ${ }^{4}$ dos $4^{\circ}$ e $5^{\circ}$ anos do curso de graduação em Psicologia da unidade e supervisionados por uma psicóloga contratada pelo CPPA. As sessões duram cerca de cinqüenta minutos e os estagiários se revezam, de segunda a sexta-feira, em dois plantões diários de três horas. Pode-se agendar antecipadamente o atendimento junto à Recepção do CPPA ou solicitá-lo de imediato, caso haja um estagiário disponível no momento. As supervisões ocorrem semanalmente, possuem um enfoque teórico-clínico psicanalítico e são conduzidas tanto em grupo quanto individualmente.

O serviço em questão opera, antes de mais nada, como um lugar de escuta e acolhimento. No entanto, o PPAPA pode também desempenhar o papel que compete a um serviço de triagem e encaminhamento, como discutiremos adiante. Os procedimentos adotados, conseqüentemente, são variáveis, como ilustra a Figura 1. A intervenção pode limitar-se a apenas uma sessão de pronto-atendimento, podem ser realizadas 2 ou 3 sessões e o aluno ser encaminhado, para psicoterapia individual e de grupo, para outros serviços vinculados ao Programa e/ou serem introduzidas novas estratégias de atendimento, se necessário.

Dessa forma, parece-nos possível afirmar que, em linhas gerais, o PPAPA guarda algumas semelhanças tanto com o "tratamento de ensaio" postulado por Freud (1994/1911c) quanto com as "entrevistas preliminares" propostas por Lacan (Wachsberger, 1989; Priszkulnik, 1998), pois visa oferecer um acolhimento inicial ao usuário e coligir dados para a definição do direcionamento

\footnotetext{
(4) Aprovados em um processo seletivo que ocorre anualmente e possui basicamente dois pré-requisitos: o contato prévio com a área clínica e a experiência de psicoterapia pessoal.
} 
da intervenção. Cumpre assinalar, contudo, que, independentemente do número de sessões de pronto-atendimento e/ou do encaminhamento do caso, esse acolhimento inicial se afigura, por si só, como uma intervenção, uma vez que representa, mais do que uma mera oportunidade para a coleta de informações supostamente importantes, um espaço privilegiado que pode levar o usuário a refletir sobre suas queixas (Salinas \& Santos, 2002).

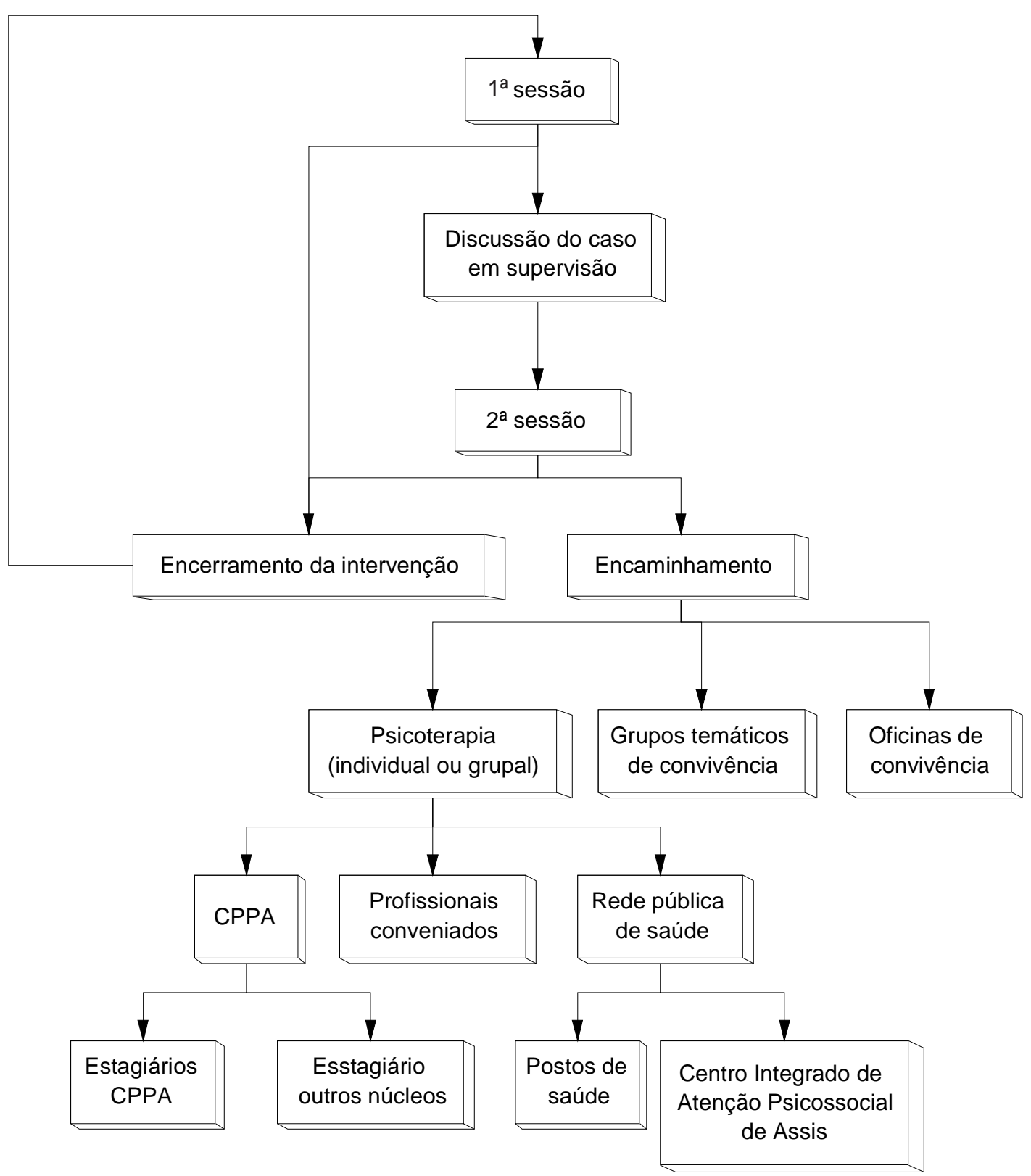

Figura 1. Fluxograma das estratégias de atendimento do PPAPA. 


\section{CONSIDERAÇÕES ACERCA DAS ESTRATÉGIAS DE INTERVENÇÃOE MODALIDADES DE ATENDIMENTO}

Muitos usuários procuram o serviço alegando problemas de convívio com companheiros de moradia, ansiedade e estresse em virtude das atividades acadêmicas e outras dificuldades aparentemente circunstanciais. $\mathrm{Na}$ maioria das vezes, tais queixas sugerem, a princípio, que os sujeitos estão sendo supostamente acometidos por um sofrimento psíquico "leve" e denotam, conseqüentemente, a existência de uma demanda de escuta e acolhimento. Os estagiários responsáveis pelo atendimento desse tipo de casos, não obstante, em vez de partir de uma escuta a priori, procuram investigar a suposição sobre a qual se funda a demanda do usuário, com o intuito de verificar se há algo para além da queixa (Silvestre, 1987).

No entanto, a experiência do serviço sugere que a maioria dos usuários que apresenta queixas dessa categoria tende a não direcionar seus questionamentos para si próprios e a não se incluir em seus sintomas. Muitos deles, na realidade, explicitam que procuraram o serviço apenas para "desabafar" e que não têm interesse em dar início a um processo psicoterapêutico. Nesses casos, usualmente o serviço faz as vezes de um espaço de escuta e acolhimento emergencial e a intervenção limita-se a apenas uma sessão de pronto-atendimento. De qualquer forma, o estagiário responsável coloca-se à disposição para uma segunda sessão, que pode ser agendada para a semana subseqüente ou solicitada posteriormente, caso o usuário julgue necessário.

Em contrapartida, muitos alunos apresentam-se ao PPAPA com queixas que denotam a existência de uma demanda de tratamento, tais como tentativas de suicídio e uso excessivo de álcool e/ou drogas. Nessas ocasiões, o estagiário responsável procura, já na primeira sessão, conduzir o usuário à retificação subjetiva, ou seja, promover a "passagem do fato de queixarse dos outros para queixar-se de si mesmo"
(Miller, 1997, p. 255). Para tanto, problematiza as justificativas utilizadas pelo usuário para explicar as próprias queixas e, ao mesmo tempo, procura possibilitar a formulação de novas questões a partir de um outro prisma (Mannoni, 1980; Kehl, 2002).

O estagiário que realiza o atendimento de um usuário que apresenta queixas que denotam a existência de uma demanda de tratamento invariavelmente propõe uma segunda sessão na semana subseqüente - ou até mesmo ao final da semana do primeiro atendimento, se necessário -, antes de sugerir qualquer espécie de encaminhamento. Desse modo, tem-se tempo hábil para que o caso possa ser devidamente analisado em supervisão e seja possível, conseqüentemente, delinear o(s) encaminhamento(s) mais adequado(s) a ser(em) sugerido(s) e discutido(s) no segundo atendimento.

Dificuldades de adaptação à cidade também são queixas reiteradamente mencionadas pelos usuários do serviço. A princípio, poder-seia supor que tais dificuldades são essencialmente circunstanciais. No entanto, a experiência do PPAPA tem evidenciado que muitos dos alunos que procuram o serviço com queixas dessa categoria apresentam não apenas uma demanda de adaptação, mas principalmente dificuldades veladas - e muitas vezes severas - de se desligar e se distanciar das pessoas queridas da cidade de origem e estabelecer novos vínculos em Assis. Assim sendo, o estagiário responsável pelo atendimento de um usuário que refere dificuldades de adaptação realiza uma primeira sessão e sugere um segundo atendimento na semana subseqüente, para que o caso possa ser devidamente analisado em supervisão nesse ínterim.

Todos os casos que não se limitam apenas ao pronto-atendimento são, portanto, relatados em supervisão antes da segunda sessão. Tal procedimento é adotado levando-se em conta que, a despeito de haver uma certa uniformidade no que diz respeito às queixas iniciais dos usuários, obviamente existem variantes individuais importantíssimas a serem consideradas 
para que seja possível a adequada compreensão de cada caso. Dessa forma, a supervisão, como se vê na Figura 2, representa um espaço de discussão dos atendimentos e contribui para que se possam elaborar hipóteses diagnósticas ponderadas e, conseqüentemente, delinear o(s) encaminhamento(s) mais apropriado(s) a ser(em) sugerido(s) para cada um dos usuários que recorrem ao serviço.

Na segunda sessão, o estagiário responsável apresenta as diferentes modalidades de encaminhamento, esclarece as particularidades de cada uma delas, sugere ao usuário aquela(s) considerada(s) mais pertinente(s) para o caso e verifica a disponibilidade e o interesse do mesmo em aceitá-la(s). Os usuários do PPAPA têm à disposição, como observado anteriormente na Figura I, quatro diferentes modalidades de encaminhamento, a saber: a) psicoterapia individual; b) psicoterapia em grupo; c) grupos de convivência com temáticas específicas; e/ou d) oficinas de convivência.

Os usuários encaminhados para psicoterapia individual ou de grupo podem ser atendidos gratuitamente no CPPA - por estagiários do PPAPA ou de outros núcleos de estágio - ou por profissionais da rede pública do município, vinculados aos postos de saúde ou ao Centro Integrado de Atenção Psicossocial de Assis (CIAPS). Ademais, caso não haja vagas disponíveis nos serviços públicos, os usuários encaminhados para psicoterapia podem procurar profissionais da cidade conveniados ao PPAPA, que oferecem condições mais acessíveis de pagamento a alunos da UNESP/Assis.

Os grupos de convivência visam favorecer a integração dos alunos do campus, são abertos e regulares, possuem temas específicos e diversificados (teatro, sexualidade e esportes, dentre outros) e são promovidos por professores e funcionários da unidade ou estagiários do CPPA. As oficinas de convivência possuem objetivos análogos e também são conduzidas por estagiários, funcionários e/ou professores, mas são realizadas esporadicamente ao longo do ano letivo e não possuem temáticas específicas.

1) I.O.: Instante de ouvir

2) T.E.: Tempo de elaborar

3) M.C.: Momento de "concluir"

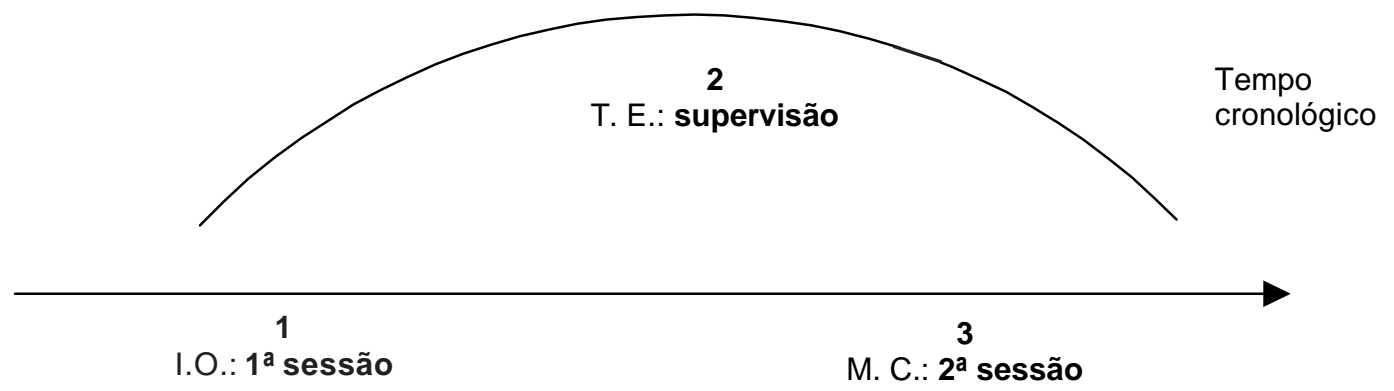

Figura 2*. Três tempos lógicos para a definição do desfecho das intervenções que não se limitam ao pronto-atendimento.

\footnotetext{
(") Figura inspirada no modelo gráfico utilizado por Lacan (1998) para diferenciar os três tempos lógicos da demanda do paciente perante a instituição.
} 
Cumpre assinalar, por fim, que o delineamento do(s) encaminhamento(s) a ser(em) sugerido(s) é definido essencialmente de acordo com as particularidades subjetivas do sujeito em questão, e não somente a partir das queixas iniciais apresentadas. Assim sendo, se um usuário que inicialmente se queixa de dificuldades de adaptação mostrar-se capaz de direcionar seus questionamentos para si e chegar à conclusão de que possui, na realidade, dificuldades de se distanciar das pessoas queridas da cidade de origem, possivelmente o estagiário responsável privilegiará a psicoterapia como modalidade de encaminhamento, e não os grupos temáticos ou as oficinas, como se poderia supor. Em contrapartida, se um usuário procurar o serviço por causa do consumo abusivo de bebidas alcoólicas e não demonstrar qualquer indício de implicação com o próprio sintoma, provavelmente o encaminhamento para psicoterapia será preterido no momento, e a possibilidade de sugerir a participação em um grupo de convivência será privilegiada, ao contrário do que ocorreria se fosse feito um encaminhamento pautado apenas pela queixa inicial - e que não levasse em consideração a dinâmica psíquica do sujeito.

\section{SOBRE O MANEJO DE ALGUMAS QUESTÕES TÉCNICAS EÉTICAS}

Tendo em vista as particularidades que caracterizam o PPAPA, a efetividade do serviço mostra-se intimamente associada à observação de algumas questões éticas e técnicas. A despeito de não termos como objetivo discutir pormenorizadamente esse assunto no presente estudo, consideramos relevante destacar que o manejo de tais questões é norteado basicamente em virtude de quatro "cuidados especiais", inspirados nas recomendações propostas por
Freud nos escritos sobre a técnica psicanalítica (1994/1911a; 1994/1911b; 1994/1911c).

Em primeiro lugar, procura-se evitar que os usuários venham a ser atendidos por estagiários com os quais já tenham tido anteriormente algum contato social relevante ${ }^{5}$. Tal precaução é adotada levando-se em conta que, caso o usuário e o estagiário já se conheçam, possi-velmente haverá, antes mesmo do início da sessão, uma atitude transferencial efetivamente estabelecida, o que poderá criar dificuldades para o desenvolvimento da intervenção (Freud, 1994/1911a). Assim sendo, os estagiários verificam, um dia antes dos plantões, o nome dos usuários que agendaram atendimento previamente e solicitam, se necessário, a troca de horário de plantão com outro estagiário. No entanto, quando um usuário solicita atendimento de imediato no horário de plantão de um estagiário com o qual já tenha tido algum contato anterior, adota-se uma estratégia diferenciada: pode-se,em virtude e da urgência do caso, abrir uma exceção ao procedimento-padrão e realizar o atendimento ou até mesmo agendar um outro horário para que o usuário possa ser atendido por um outro estagiário. Cumpre assinalar, contudo, que situações desse tipo não ocorrem com freqüência, pois a maioria dos atendimentos é agendada previamente.

Em segundo lugar, durante as supervisões dedica-se uma especial atenção à análise dos fenômenos transferenciais e contratransferenciais, com o intuito de subsidiar o adequado manejo dos sentimentos inconscientes do usuário para com o estagiário e vice-versa. A experiência do PPAPA tem evidenciado que, ao contrário do que se poderia pensar, o fato de o serviço ser conduzido por estagiários não intensifica a manifestação de resistências transferenciais, pois os usuários tendem a atribuir antecipadamente - e inconscientemente - um suposto saber ao responsável pelo atendimento, o que contribui, na maioria das vezes, para o

(5) Em linhas gerais, os estagiários evitam, sempre que possível, o atendimento de alunos com os quais: a) já tenham tido qualquer espécie de envolvimento afetivo; b) tenham amigos próximos em comum; c) já tenham tido algum contato próximo em função de atividades discentes (aulas, estágios, grupos de estudo, etc.) e d) já tenham mantido qualquer outro tipo de relacionamento que possa comprometer o atendimento. 
desenvolvimento da intervenção (Wachsberger, 1989). De qualquer forma, esse suposto saber deve ser manejado com desvelo para que não se transforme, no decorrer dos atendimentos, em sentimentos excessivamente afetuosos (amor transferencial) ou hostis (transferência negativa), o que, indubitavelmente, acarretaria maiores dificuldades ao trabalho.

Por outro lado, a análise da contratransferência também tem se mostrado de significativa importância, uma vez que a situação do PPAPA pode eventualmente levar os estagiários menos experientes a utilizar técnicas afetivas ou influências sugestivas (Freud, 1994/1911b) para estimular a expressão de conteúdos inconscientes por parte dos usuários. No entanto, tais estratégias, a despeito de parecerem, a princípio, profícuas e justificáveis, mostram-se efetivamente contraproducentes a longo prazo, uma vez que, em última análise, colocam o usuário em condições de igualdade com o estagiário e, assim, eliminam o suposto saber anteriormente atribuído pelo primeiro ao segundo, dificultando, conseqüentemente, a continuidade da intervenção.

Em terceiro lugar, o delineamento do setting é enfatizado, para que o usuário possa compreender com clareza as possibilidades e limitações do PPAPA. Dessa forma, procura-se evitar que o usuário tenha uma expectativa inadequada em relação ao serviço e, por conseguinte, se decepcione com o desfecho da intervenção. Ademais, ao delimitar o setting, o estagiário responsável pelo atendimento preocupa-se em esclarecer ao usuário que o espaço de escuta oferecido pelo serviço se restringe à clínica-escola. Tal procedimento é adotado com o intuito de evitar qualquer tipo de constrangimento para ambos em eventuais encontros em outras dependências do campus.

Em quarto lugar, por fim, os discentes de Psicologia que recorrem ao PPAPA e são encaminhados para psicoterapia, seja ela individual ou de grupo, mantêm contato com os estagiários apenas no pronto-atendimento, uma vez que, nas situações em que se nota a necessidade de proceder ao encaminhamento de um usuário vinculado ao curso em questão para a referida modalidade de atendimento, a psicóloga responsável pela supervisão do serviço assume o caso e dá continuidade à intervenção. Tal precaução é tomada levando-se em conta que, se o usuário fosse atendido em psicoterapia por um colega de curso, poderiam surgir diversas resistências - potencializadas por processos de identificação - que possivelmente colocariam em risco a resolubilidade da intervenção.

Além de contribuir para a efetividade do serviço, tais "cuidados especiais" - assim como outros menos ilustrativos, mas igualmente relevantes - têm indicado que novas práticas clínicas de orientação psicanalítica podem ser implementadas satisfatoriamente no contexto institucional. Para tanto, contudo, faz-se necessário o emprego de técnicas e estratégias de atendimento que diferem, em maior ou menor grau, daquelas usualmente utilizadas no âmbito da clínica particular. Evidencia-se, assim, que, como salientam Salinas e Santos (2002), a adequação da técnica à ética - e não o contrário -, torna possível a implementação de novas modalidades psicoterapêuticas, pautadas pelo método psicanalítico, no âmbito das instituições.

\section{PROPOSTAS DE REFORMULAÇÃO DO FUNCIONAMENTO DO SERVIÇO}

Inicialmente, o PPAPA funcionava, como o próprio nome do serviço evidencia, basicamente como um lugar de escuta e acolhimento, uma vez que se fazia necessário organizar os recursos da instituição antes de implementar novas práticas. Assim sendo, após a realização de uma ou duas sessões de pronto-atendimento, a intervenção se dava por encerrada ou o usuário era encaminhado para psicoterapia individual no CPPA, onde tal modalidade de atendimento já era regularmente oferecida. No entanto, a partir do momento em que a organização dos recursos atingiu o nível esperado, foi possível iniciar a implementação de outras estratégias de 
intervenção. Para tanto, mostrou-se impresindível a parceria com professores da unidade, funcionários do campus, estagiários de outros núcleos, profissionais autônomos e/ou vinculados à rede pública de saúde do município. Como resultado desse processo, o CPPA passou a oferecer psicoterapia de grupo como uma nova possibilidade de encaminhamento para os usuários do serviço. A seguir, foram implementados os grupos temáticos e ampliadas as vagas para psicoterapia individual, também junto ao CPPA. Por fim, foram criadas as oficinas de convivência e ampliadas as vagas para psicoterapia individual, mediante o estreitamento dos contatos com os profissionais da rede pública de saúde do município e o estabelecimento de convênios com profissionais autônomos.

Estudos que focalizam mais especificamente a caracterização da clientela do PPAPA (Peres \& Coelho, 2001, 2002a, 2002b) têm fornecido subsídios de extrema relevância para o planejamento de mudanças a serem implementadas na estruturação do serviço. Tendo em vista que a maioria dos alunos que recorreu ao PPAPA nos últimos anos foi encaminhada para psicoterapia individual ( $n=38$, ou seja, aproximadamente $65 \%$ dos usuários em 2000 e $n=50$, isto é, aproximadamente $63 \%$ dos usuários em 2001), tem-se pensado em ampliar ainda mais o número de vagas para tal modalidade de atendimento, tanto no CPPA como junto aos profissionais conveniados e - sobretudo - à rede pública de saúde.

Levando-se em conta que a cada ano o serviço registra um aumento significativo no número de usuários, parece relevante ampliar também o número de grupos psicoterapêuticos, pois tal estratégia de intervenção possibilita o atendimento de uma quantidade maior de sujeitos. Além disso, planeja-se reestruturar os grupos temáticos, uma vez que os mesmos foram pouco acionados ( $n=3$, isto é, aproximadamente $5 \%$ dos usuários em 2000 e $n=6$, isto é, aproximadamente $7 \%$ dos usuários em 2001) e demonstraram uma resolubilidade limitada nos dois últimos anos. As oficinas de convivência, por fim, possivelmente serão mantidas, pois têm desempenhado um papel preventivo relevante, favorecendo a integração dos alunos do campus. Cumpre assinalar, contudo, que se planeja tornálas mais sistemáticas e regulares, em vez de manter o caráter esporádico que as caracteriza atualmente.

A experiência do PPAPA tem indicado que o serviço vem sendo bem aceito pela comunidade discente interna, uma vez que a cada ano: a) a quantidade de usuários se torna mais significativa ( $n=28$ em 1998, $n=40$ em 1999, $n=58$ em 2000 e $n=79$ em 2001); b) aumenta o número de alunos atendidos que aderem ao encaminhamento sugerido ( $n=54$, aproximadamente $93 \%$ dos usuários em 2000 e $n=74$, aproximadamente 94\% dos usuários em 2001); e c) diminui a porcentagem de usuários que interrompem o serviço antes do desfecho da intervenção ( $n=4$, aproximadamente $7 \%$ dos usuários em $2000 \mathrm{e}$ $n=5$, aproximadamente $6 \%$ dos usuários em 2001). Levando-se em conta tais indicadores, pode-se pensar que o PPAPA, da maneira como está organizado atualmente, tem atingido a contento os objetivos aos quais se propõe, uma vez que tem favorecido o acesso da comunidade discente interna a uma diversificada rede de serviços psicológicos. Com as reestruturações que vêm sendo planejadas para os próximos anos, pretende-se aprimorar o serviço e ampliar ainda mais o número de atendimentos. Além disso, pretende-se, a médio prazo, criar novos serviços auxiliares de apoio psicológico e implementar ações de caráter preventivo.

\section{CONSIDERAÇÕES FINAIS}

A contínua reflexão acerca das modalidades de atendimento e das estratégias de intervenção colocadas em prática pelo PPAPA tem subsidiado a adequação do trabalho desenvolvido às reais necessidades da clientela e o planejamento de reestruturações na organização do serviço. Dessa forma, o PPAPA permanece constantemente aberto a reformulações, com 
o intuito de aprimorar os serviços prestados, cuja relevância vem sendo corroborada pela experiência desde sua implementação.

Cumpre assinalar, por fim, que o presente estudo pode também fornecer elementos profícuos para a criação de programas semelhantes em outras clínicas-escola, uma vez que, como destacamos anteriormente, serviços de atendimento psicológico voltados especificamente a estudantes universitários representam uma modalidade de intervenção extremamente relevante-eainda pouco explorada-na realidade do país.

\section{REFERÊNCIAS BIBLIOGRÁFICAS}

BARROS, L.; Corrêa, L.C.C. \& Germano Jr., A. (2001) Psicodiagnóstico interventivo em instituição. Em: Universidade Presbiteriana Mackenzie (Org.), Anais do I Congresso de Psicologia Clínica (pp. 79-82). São Paulo, SP.

BEZERRA Jr., B. (1987) Considerações sobre terapêuticas ambulatoriais em saúde mental. Em: S. Tundis (Org.) Cidadania e loucura: políticas de saúde mental no Brasil (pp. 133-169). Petrópolis, RJ: Vozes/Abrasco.

CALEJÓN, L.M.C. (1996) Manejo de crises e dificuldades adaptativas de universitários (Tese de Doutorado). São Paulo, SP: Universidade de São Paulo - Instituto de Psicologia.

ENÉAS, M.L.E.; Faleiros, J.C. \& Sá, A.C.A. (2000) Uso de psicoterapias breves em clínica-escola: caracterização dos processos com adultos. Psicologia: Teoria e Prática, 2 (2), pp. 9-30.

FREUD, S. (1994) A dinâmica da transferência (J.O.A. Abreu, Trad.). Em: J. Salomão (Org.), Edição Standard Brasileira das Obras Completas de Sigmund Freud (Vol. XII). Rio de Janeiro, RJ: Imago (original publicado em 1911a).

FREUD, S. (1994) Recomendações aos médicos que exercem a psicanálise (J.O.A. Abreu,
Trad.). Em: J. Salomão (Org.), Edição Standard Brasileira das Obras Completas de Sigmund Freud (Vol. XII). Rio de Janeiro, RJ: Imago (original publicado em 1911b).

FREUD, S. (1994) Sobre o início do tratamento (J.O.A. Abreu, Trad.). Em: J. Salomão (Org.), Edição Standard Brasileira das Obras Completas de Sigmund Freud (Vol. XII). Rio de Janeiro, RJ: Imago (original publicado em 1911c).

HERZBERG, E. (1996) Reflexões sobre o processo de triagem de clientes a serem atendidos em clínicas-psicológicas-escola. Em: R.M.L.L. Carvalho (Org.) Repensando a formação do psicólogo: da informação à descoberta (pp. 147-154). Campinas, SP: Alínea (Coletâneas da ANPEPP, v. 1, n. 9).

KEHL, M.R. (2002) Sobre ética e psicanálise. São Paulo, SP: Companhia das Letras.

LACAN, J. (1998) Escritos (V. Ribeiro, Trad.). Rio de Janeiro, RJ: Jorge Zahar.

MANNONI, M. (1980) A primeira entrevista em psicanálise (R.C. Lacerda, Trad.). Rio de Janeiro, RJ: Campus.

MILLER, J.-A. (1997) Lacan elucidado. Rio de Janeiro, RJ: Jorge Zahar.

MITO, T.I.H. (2001) Psicoterapia breve infantil: eixos norteadores do processo. Em: Universidade Presbiteriana Mackenzie (Org.), Anais do I Congresso de Psicologia Clínica (pp. 157-163). São Paulo, SP.

PERES, R.S. \& Coelho, H.M.B. (2001) Caracterização dos usuários do pronto-atendimento psicológico da clínica-escola da UNESP/Assis em 2000. Em: Universidade Federal de São Carlos (Org.), Anais do IX Congresso de Iniciação Científica da UFSCar (CD-ROM). São Carlos, SP.

PERES, R.S. \& Coelho, H.M.B. (2002a) Perfil sócio-demográfico dos usuários do Programa de Pronto-Atendimento Psicológico ao Aluno da UNESP/Assis em 2001. Em: Universidade Federal de São Carlos (Org.), Anais do X Congresso de Iniciação Científica da UFSCar (CD-ROM). São Carlos, SP. 
PERES, R.S. \& Coelho, H.M.B. (2002b) Perfil clínico dos usuários do Programa de ProntoAtendimento Psicológico ao Aluno da UNESP/Assis em 2001: das queixas iniciais ao encaminhamento. Em: Universidade Federal de São Carlos (Org.), Anais do X Congresso de Iniciação Científica da UFSCar (CD-ROM). São Carlos, SP.

PRISZKULNIK, L. (1998) As entrevistas diagnósticas em Psicanálise. Psychê 2 (2), pp. 17-23.

SALINAS, P. \& Santos, M.A. (2002) Serviço de triagem em clínica-escola de psicologia: a escuta analítica em contexto institucional. Psychê 6 (9), pp. 177-196.

SANTOS, M.A. (1987) O psicodiagnóstico infantil em grupo: uma experiência em instituição. Arquivos Brasileiros de Psicologia 39 (2), pp. 3-17.

SANTOS, M.A.; Moura, L.; Pasian, S.R. \& Ribeiro, P.L.L. (1993) Caracterização da clientela de adolescentes e adultos de uma clínica-escola de Psicologia. Psicologia: Teoria e Pesquisa 9 (1), pp. 123-144.

SILVARES, E.F.M. (1996) É satisfatório o atendimento psicológico nas clínicas-escola brasileiras? Em: R.M.L.L. Carvalho (Org.) Repensando a formação do psicólogo: da informação à descoberta (pp. 137-147). Campinas, SP: Alínea (Coletâneas da ANPEPP, v. 1, n. 9).
SILVARES, E.F.M. (2000) Invertendo o caminho tradicional do atendimento psicológico em uma clínica-escola brasileira. Estudos de Psicologia (RN) 5 (1), pp.149-180.

SILVESTRE, D. (1987) Problemas y particularidades de la demanda de analisis en institución. Em: E. Laurent (Org.) El significante de la transferencia (pp. 89-94). Buenos Aires, Manantial.

SIMON, R. (1971) "O complexo tanatolítico" justificando medidas de psicologia preventiva para estudantes de medicina. Boletim de Psiquiatria 4 (4), pp. 113-115.

TOZONI-REIS, J.R. (1994) Psicoterapia na rede pública de saúde. Temas em Psicologia 2, pp. 177-188.

VAISBERG, T.M.J.A. \& Machado, M.C.L (1999) Diagnóstico estrutural de personalidade em psicopatologia psicanalítica. Psicologia USP 11 (1), pp. 29-48.

WACHSBERGER, H. (1989) Função das entrevistas preliminares (L. Forbes, Trad.). Em: M.B. Motta (Org.) Clínica lacaniana (pp. 26-31). Rio de Janeiro, RJ: Jorge Zahar.

YAMAMOTO, K. (1997) Prevenção de distúrbios adaptativos em estudantes universitários. Mudanças 8, pp. 267-273.

Recebido para publicação em 9 de abril de 2003 e aceito em 24 de setembro de 2003. 
